\title{
El personaje principal en Aura de Carlos Fuentes y un breve acercamiento con la novela iraquí
}

\author{
The main character in Carlos Fuentes's Aura and \\ a brief approach to the Iraqi novel
}

\author{
LAYLA FADIL HASSAN \\ Facultad de Lenguas Modernas \\ Universidad de Bagdad \\ Lika Mohamed Bachir Hassan \\ Facultad de Lenguas Modernas \\ Universidad de Bagdad
}

\section{Resumen}

A finales de los años cincuenta, apareció un grupo de escritores latinoamericanos de gran trascendencia intelectual. Dentro de este grupo, conocido como boom latinoamericano, se encuentra Carlos Fuentes.

Fuentes muestra una iniciación a los misterios del tiempo y de la personalidad. Esos enigmas están implícitos en la novela Aura (1962), la cual analizaremos en este breve ensayo. Hay temas pertenecientes al boom en esta obra literaria. Asimismo, se observan elementos típicos de la difícil y compleja historia de América Latina. El mundo imaginario entre los escritores iraquíes y latinoamericanos es similar. La realidad mágica no existe únicamente en América Latina, sino también en los países de Oriente Medio, y muchos escritores árabes lo demuestran en sus trabajos literarios.

Palabras clave: Carlos Fuentes, boom latinoamericano, Aura, Oriente Medio, árabe

\section{Abstract}

At the end of the fifties, a series of Latin American writers appeared. In this group, known as Latin American Boom, was Carlos Fuentes.

Fuentes shows us an initiation into the mysteries of time and personality. These mysteries are implicit in his novel Aura (1962), which we will analyze in this brief investigation. 
There are themes of the Boom Literature in this novel, and traces of the difficult and distinguished history of Latin America. The imaginary world among Iraqi and Spanish writers is similar. The magical reality does not exist only in Latin America, but also in the countries of the Middle East, and many Arab writers took that subject into their literary works.

Keywords: Carlos Fuentes, latin american boom, Aura, middle east, arab

\section{Introducción}

A finales de los años cincuenta, apareció una serie de escritores latinoamericanos, cuya intelectualidad los popularizó y fueron nombrados como boom latinoamericano. Las coordenadas específicamente literarias del fenómeno del boom no son fácilmente delimitables, puesto que no concreta ninguna orientación narrativa.

El boom supuso para algunos autores el contacto con nuevas formas narrativas que transformaron significativamente sus trayectorias. Podemos mencionar algunos de sus integrantes o precursores: Jorge Luis Borges, Argentina; Alejo Carpentier, Cuba; Miguel Ángel Asturias, Guatemala; Juan Rulfo y Carlos Fuentes, México; Juan Carlos Onetti, Uruguay; María Luisa Bombal, Chile; y Germán Espinosa, Colombia (Shaw, 1999, pp. 123-124).

Para Fuentes, el pasado se sigue expresando en el presente; por eso, en sus novelas, subyace casi siempre todo un mundo de antiguos dioses.

El tema de la supervivencia del pasado en el presente y la reencarnación, aparecen claramente en el escenario de Aura.

Sobre todo parece fascinarle a Fuentes el tema de la supervivencia de lo pasado en lo presente y el de la reencarnación. Símbolo del primero es la mansión misteriosa que figura como escenario de Aura: abajo, superpuesto, lo moderno -relojerías, tiendas de zapatos-; arriba, el viejo palacio colonial.

En el piso de arriba sobrevive doña Consuelo, viuda de un general francés del emperador Maximiliano. Bruja arquetípica, se aprovecha de los encantos físicos de su doble (Aura) para inducir al protagonista a sellar, con la profanación de la hostia, un pacto diabólico que lo convierte en la reencarnación del difunto general (Shaw, 1999, p. 102).

\section{Análisis de la obra Aura}

Aura, una novela en miniatura, escrita totalmente en segunda persona, recurso semihipnótico que, en cierto modo, identifica al lector con el protagonista, Felipe Montero, mientras sufre una experiencia inexplicable en un viejo caserón del centro de la ciudad de México. Se alternan en esta obra verbos en el presente y el futuro para crear una impresión de una misteriosa fatalidad en torno al joven.

Hay marcas de la literatura del boom, como la pérdida de la esperanza 
y la unión del pasado que no tiene relación con el presente (la indiferencia). Como también se observa la historia del pasado difícil de los latinoamericanos.

La segunda persona del singular (tú) aparece claramente en esta novela y adentra, de alguna manera, al lector en la novela. Después de todas las condiciones, la más importante es la que indica la pérdida de la esperanza para los habitantes de aquella casa, por ejemplo, doña Consuelo dice "no tengo placer en la vida, solo la oración y la adoración" (Fuentes, 1972, p. 111).

\section{Personajes y temas}

Felipe Montero. Felipe Montero, un joven historiador y profesor a tiempo parcial en una escuela privada. Está aburrido de su trabajo de enseñar "hechos inútiles" a "alumnos soñolientos" y desea un cambio en su rutina diaria. Un día se siente atraído por un anuncio que parece dirigido personalmente a él. Inquieto y curioso, es particularmente susceptible a los extraños acontecimientos y relaciones que encuentra cuando acepta el trabajo de traducir las memorias del esposo fallecido de la Sra. Consuelo Llorente. Felipe deja el mundo exterior conocido y entra en el hogar oscuro y mohoso de Consuelo; en este entorno misterioso y gótico, conoce a Aura, la sobrina de la anciana.

En la novela, encontramos tres tipos de personajes principales y los tres derivados del personaje núcleo en la novela: Felipe Montero. Aunque la novela lleva el nombre de uno de los personajes, el papel de Aura es secundario en comparación con el de Montero, porque él se considera más real física y emocionalmente que las dos mujeres, la vieja y la joven.
Si leemos profundamente la novela, encontramos que el papel de las dos mujeres puede integrarse para simbolizar una mujer en la juventud y la vejez, puesto que no se separan y la desaparición de una no se considera una desaparición completa con la presencia de la segunda.

- Aura. Mi compañera. Mi sobrina.

- Buenas tardes.

La joven inclinará la cabeza y la anciana, al mismo tiempo que ella, remedará el gesto (Fuentes, 1972, p. 12).

Las dos mujeres hacen los mismos actos aunque no estén en el mismo lugar, como si fueran un alma en dos cuerpos:

Arrojas los papeles a un lado y desciendes, sospechando el único lugar donde Aura podrá estar en las mañanas: el lugar que le habrá asignado esta vieja avara. La encuentras en la cocina, sí, en el momento en que degüella un macho cabrío: el vapor que surge del cuello abierto, el olor de sangre derramada, los ojos duros y abiertos del animal te dan náuseas: detrás de esa imagen, se pierde la de una Aura mal vestida, con el pelo revuelto, manchada de sangre, que te mira sin reconocerte, que continúa su labor de carnicero. Le das la espalda: esta vez, hablarás con la anciana, le echarás en cara su codicia, su tiranía abominable. Abres de un empujón la puerta y la ves, detrás del velo de luces, de pie, cumpliendo su oficio de aire: la ves con las manos en movimiento, extendidas en el aire: una mano 
extendida y apretada, como si realizara un esfuerzo para detener algo, la otra apretada en torno a un objeto de aire, clavada una y otra vez en el mismo lugar. En seguida, la vieja se restregará las manos contra el pecho, suspirará, volverá a cortar en el aire, como si — si, lo verás claramente: como si despellejara una bestia... Corres al vestíbulo, la sala, el comedor, la cocina donde Aura despelleja al chivo lentamente, absorta en su trabajo, sin escuchar tu entrada ni tus palabras, mirándote como si fueras de aire (Fuentes, 1972, pp. 32-33).

La imagen es más clara en este párrafo:

Y cuando te estés secando, recordarás a la vieja y a la joven que te sonrieron, abrazadas, antes de salir juntas, abrazadas: te repites que siempre, cuando están juntas, hacen exactamente lo mismo: se abrazan, sonríen, comen, hablan, entran, salen, al mismo tiempo, como si una imitara a la otra, como si de la voluntad de una dependiese la existencia de la otra (Fuentes, 1972, p. 40).

\section{México}

México fue forzado a vivir en la oscuridad, arrojando papeles del pasado a las ratas; el polvo de los años se ha acumulado sobre estos solo para mantener a México en su lugar en el pasado. En un vano e inútil acto, hay quienes quieren que este país permanezca esclavo del colonizador para restringir el poder de los jóvenes y matar su amor por la vida. Unos de los símbolos de la juventud son la libertad y la mirada optimista hacia el futuro; sin embargo, el mundo de la novela está lleno de oscuridad:

Cierras el zaguán detrás de ti e intentas penetrar la oscuridad de ese callejón techado - patio, porque puedes oler el musgo, la humedad de las plantas, las raíces podridas, el perfume adormecedor y espeso-. Buscas en vano una luz que te guíe. Buscas la caja de fósforos en la bolsa de tu saco pero esa voz aguda y cascada te advierte desde lejos:

-No... no es necesario. Le ruego. Camine trece pasos hacia el frente y encontrará la escalera a su derecha. Suba, por favor. Son veintidós escalones.

Cuéntelos.

Trece. Derecha. Veintidós (Fuentes, 1972, p. 6).

Lees esa misma noche los papeles amarillos, escritos con una tinta color mostaza; a veces, horadados por el descuido de una ceniza de tabaco, manchados por moscas. El francés del general Llorente no goza de las excelencias que su mujer le habrá atribuido. Te dices que tú puedes mejorar considerablemente el estilo, apretar esa narración difusa de los hechos pasados [...] (Fuentes, 1972, p. 21).

\section{Presente/pasado}

El personaje principal representa el presente y su lucha con el pasado y cómo con sus ideas intenta atraer a la nueva generación y aislarla del mundo 
exterior, como se menciona en el siguiente párrafo de la novela:

Cierras el zaguán detrás de ti e intentas penetrar la oscuridad de ese callejón techado - patio, porque puedes oler el musgo, la humedad de las plantas, las raíces podridas, el perfume adormecedor y espeso-. Buscas en vano una luz que te guíe. Buscas la caja de fósforos en la bolsa de tu saco pero esa voz aguda y cascada te advierte desde lejos:

-No... no es necesario. Le ruego. Camine trece pasos hacia el frente y encontrará la escalera a su derecha. Suba, por favor. Son veintidós escalones. Cuéntelos. Trece. Derecha. Veintidós.

El olor de la humedad, de las plantas podridas, te envolverá mientras marcas tus pasos, primero sobre las baldosas de piedra, enseguida sobre esa madera crujiente, fofa por la humedad y el encierro. Cuentas en voz baja hasta veintidós y te detienes, con la caja de fósforos entre las manos, el portafolio apretado contra las costillas. Tocas esa puerta que huele a pino viejo y húmedo; buscas una manija; terminas por empujar y sentir, ahora, un tapete bajo tus pies. Un tapete delgado, mal extendido, que te hará tropezar y darte cuenta de la nueva luz, grisáceo y filtrado, que ilumina ciertos contornos.

-Señora — dices con una voz monótona, porque crees recordar una voz de mujer-Señora...
- Ahora a su izquierda. La primera puerta. Tenga la amabilidad. (Fuentes, 1972, pp. 6-7).

Es la oscuridad del pasado y el rechazo a vivir en la luz y, por supuesto, la reacción simboliza el color oscuro, mientras que cada evolución aumenta la luz de la vida y el pensamiento. La atmósfera de la casa donde se desarrolla la historia es en general muy oscura.

Incluso, hay una resistencia a la idea de salir de la casa nuevamente, como se menciona en el siguiente diálogo:

—Ah! Olvidé que un cajón de mi mesa está cerrado con llave. Allí tengo mis documentos. Y ella murmurará:

—Entonces... ¿quiere usted salir?

Lo dice como un reproche. Tú te sientes confundido y alargas la mano con el llavín colgado de un dedo, se lo ofreces.

—No urge (Fuentes, 1972, p. 17).

Una de las imágenes de la esclavitud es el mundo cerrado y una versión a las manifestaciones más simples de la libertad, como se establece en este diálogo:

-No, no, no. No me adelante su opinión. Trabaje sobre esos papeles y cuando termine le pasaré los demás.

—Está bien, señora. ¿Podría visitar el jardín?

— ¿Cuál jardín, señor Montero?

—El que está detrás de mi cuarto. 
- En esta casa no hay jardín. Perdimos el jardín cuando construyeron alrededor de la casa.

-Pensé que podría trabajar mejor al aire libre.

-En esta casa solo hay ese patio oscuro por donde entró usted. Allí mi sobrina cultiva algunas plantas de sombra. Pero eso es todo (Fuentes, 1972, p. 23).

Las ideas coloniales existen en la mente de la vieja generación; el conejo que vive y se mueve libremente con la anciana en su cama es un símbolo de la colonización española. España alguna vez fue referida como la tierra de los conejos.

[...] al extender la mano no tocas otra mano, sino la piel gruesa, afieltrada, las orejas de ese objeto que roe con un silencio tenaz y te ofrece sus ojos rojos: sonríes y acaricias al conejo que yace al lado de la mano que, por fin, toca la tuya con unos dedos sin temperatura que se detienen largo tiempo sobre tu palma húmeda, la voltean y acercan tus dedos abiertos a la almohada de encajes que tocas para alejar tu mano de la otra.

—Felipe Montero. Leí su anuncio

[...] las manos pálidas que descansan sobre el vientre: solo puedes fijarte en el rostro, hasta que un movimiento del conejo te permite desviar la mirada y observar con disimulo esas migajas, esas costras de pan regadas sobre los edredones de seda roja, raídos y sin lustre
Entonces te darás cuenta de que es una cama apenas elevada sobre el ras del suelo, cuando el conejo salte y se pierda en la oscuridad [el subrayado es nuestro] (Fuentes, 1972, pp.7-8).

Aquí es posible señalar en la novela, los animales que encontramos como las ratas en la habitación y los gatos fuera de la casa, pero a la anciana no le importan sólo el conejo.

-Señora... Hay un nido de ratones en aquel rincón...

— ¿Ratones? Es que yo nunca voy hasta allá...

-Debería usted traer a los gatos aquí.

—_Gatos? ¿Cuáles gatos? Buenas noches. Voy a dormir. Estoy fatigada.

—Buenas noches (Fuentes, 1972, p. 9).

\section{Doble personalidad}

Ya hemos mencionado la doble personalidad femenina. Ahora bien, el personaje principal también tiene doble personalidad: al final de la novela, encontramos un intercambio de papeles entre el joven y el marido. El joven, quien escribe las memorias del difunto marido, refleja su papel frente a la joven Aura. Ella toma el rol de la esposa y se convierte en una anciana sin previo aviso.

[...] la muchacha de ayer - cuando toques sus dedos, su talle- no podía tener más de veinte años; 
la mujer de hoy - $-y$ acaricies su pelo negro, suelto, su mejilla pálida- parece de cuarenta: algo se ha endurecido, entre ayer y hoy, alrededor de los ojos verdes; el rojo de los labios se ha oscurecido fuera de su forma antigua, como si quisiera fijarse en una mueca alegre, en una sonrisa turbia: como si alternara, a semejanza de esa planta del patio, el sabor de la miel y el de la amargura (Fuentes, 1972, p. 36).

No habrá salvación a menos de que realmente muera:

- Trata de enterrarte en vida. Tienes que renacer, Aura...

- Hay que morir antes de renacer. No. No entiendes. Olvida, Felipe; tenme confianza.

- Si me explicaras [...] (Fuentes, 1972, p. 42).

Pero los jóvenes no deberían ser influenciados por los tentadores llamados de estas fuerzas negativas ni la libertad de todas las restricciones. Esto es lo que el escritor mexicano quería transmitir a los lectores. Cuando mencionó al final de su novela:

Hundirás tu cabeza, tus ojos abiertos, en el pelo plateado de Consuelo, la mujer que volverá a abrazarte cuando la luna pase, tapada por las nubes, los oculte a ambos, se lleve en el aire, por algún tiempo, la memoria de la juventud, la memoria encarnada.

—Volverá, Felipe, la traeremos juntos. Deja que recupere fuerzas y la haré regresar (Fuentes, 1972, p. 50).

\section{Una aproximación con la novela iraquí (Al-Shamaeya)}

Después de períodos llenos de tensión política en América Latina, aparecieron de forma abundante novelas fantásticas, que reflejan desde esta temática los sufrimientos de los pueblos. Los novelistas mexicanos registraron los sucesos de su país y plasmaron sus ideas y opiniones sin tener miedo del control del gobierno. Ellos disfrazaron sus denuncias con una máscara de imaginación mágica y de esto surgió el término: realismo mágico en Hispanoamérica.

No han sido solo los hispanoamericanos los únicos que han sufrido por varios años la injusticia y opresión; también, los países árabes vivieron difíciles períodos debido a fuerzas coloniales. Podemos afirmar que Irak es un ejemplo vivo de sufrimientos e injusticias. Los intelectuales iraquíes relataron lo sucedido en varios estilos para llevar a las generaciones del futuro sus sufrimientos; por eso, encontramos la tinta de la tristeza. Esta es una señal prevalente que expresa el peso de las preocupaciones de los literarios iraquíes. Después de un análisis de la literatura de los escritores iraquíes, encontramos muchas características de las novelas del realismo mágico.

Cuando estudiamos la novela $\mathrm{Al}$ Shamaeya (que significa El manicomio) del famoso escritor iraquí AbdAlsatar Nasir, encontramos en ella muchos elementos narrativos y artísticos que podemos comparar con la estructura de la novela mexicana Aura. Los dos escritores pudieron reflexionar sobre lo que siente el personaje principal en el transcurso de su existencia; su estado psicológico mientras está en un lugar entre el pasado y el presente. 
El tiempo y el lugar presentan dos elementos básicos para especificar los efectos de los contextos literarios.

1. El lugar determina la existencia a través de la mirada del narrador.

2. El tiempo reflexiona sobre la visión del presente y el pasado.

También la descripción estuvo presente. Ambos escritores detallan lugares y los personajes; se acerca al lector al contexto y se logra el acercamiento mental y conceptual entre el receptor y el texto novelístico.

En cuanto al personaje principal, en las dos novelas, es un actor singular y alrededor de él giran los eventos y aparecen los sentimientos de misterio, confusión y rebelión, y el intento de contener el ambiente donde vive y entender los personajes que le rodean. Hay una similitud entre el personaje principal Felipe Montero, en la obra Aura, y Amin Hashim Bitar, el protagonista en la obra Al-Shamaeya. Los dos personajes intentan encontrar un sitio seguro y trabajar en silencio para ganarse la vida.

La historia termina por convertir el sitio inofensivo en un sitio agresivo. Queda la gran pregunta: ¿cuál es el secreto de la gente con quien se vive? Se termina por comprender, en el caso con los dos protagonistas, que son engañados.

\section{Conclusión}

La literatura de Fuentes ha manifestado siempre una gran lucidez en lo relacionado a los problemas políticos y culturales de México. En su literatura, se evidencia a México como un país multicultural donde los acontecimientos cotidianos actuales tienen una estrecha relación con el pasado.

La novela, aunque tiene como título el nombre de uno de los personaje, este no es el principal. El personaje principal es México, que se ha visto obligado a vivir entre las ruinas del pasado, lo que no permite que viva de manera independiente y sea el dueño de su propio destino como nación.

El personaje principal tiene doble personalidad. Al final de la novela encontramos un intercambio de papeles entre el joven y el difunto marido, y entre Aura y la anciana.

Para aclarar el hecho de que la literatura mexicana tiene similitudes con la iraquí, vale mencionar que los mundos imaginarios de los escritores iraquíes y latinoamericanos son similares. La realidad mágica no resuena únicamente en América Latina, sino también en los países de Medio Oriente.

\section{Bibliografía}

Befumo Boschi, L. y Calabrese, E. (1974). Nostalgia del futuro en Carlos Fuentes. Buenos Aires.

Benedetti, M. (1971). "Carlos Fuentes". En: Helmy G. (ed). (1971). Homenaje a Carlos Fuentes. Nueva York.

Alianza Diccionarios. (1993). Diccionario de Literatura Española Hispanoamericana (A-M). Madrid: Alianza.

Carrillo, G. (1970). "Notas sobre Zona Sagrada", $R$ y F, 19.

Durán, G. (1976). La magia y las brujas en la obra de Carlos Fuentes. México.

Elena de Valdés, M. (1998). "Carlos Fuentes and the Subversion of the 
Social Order for Women". En: The Shattered Mirror. Representations of Women in Mexican Literature, Universidad de Texas.

Fernández, T., Millares, S., y Becerra, E. (1995). Historia de la Literatura Hispanoamericana. Madrid: Editorial Universitas.

Fuentes, C. (1972). Aura. México: ISBN: 968-411-181-9.

(1991). La Campaña. México: Fondo de Cultura Económica.

(1980). Una familia lejana. México: Era.
García Gutiérrez, G. (1988). "Cristóbal Nonato". Nuevo Texto Crítico. México, núm. 1.

L. Shaw, D. (1999). Nueva Narrativa Hispanoamericana (Boom, Posboom, Posmodernismo) (6. ${ }^{a}$ edición ampliada). Madrid: Ediciones Cátedra.

Rodríguez Monegal, E. (1978). El Arte de narrar. Caracas: Monte Ávila, Editores.

Sáinz de Medrano, L. (1992). Historia de la Literatura Hispanoamericana (Desde el Modernismo). Madrid: Taurus Ediciones. 
